\title{
Pleomorphic xanthoastrocytoma at the pineal region: rare case report with successful surgical management
}

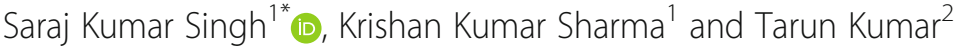

\begin{abstract}
Background: Pineal region tumors are commonly present in the pediatric age group. However, pleomorphic xanthoastrocytoma (PXA) is very rare at this region, and only few case reports have been reported till now in literature.

Case presentation: Here, we report a rare case of pineal region, juxta-thalamic, pleomorphic xanthoastrocytoma (PXA) in an 11-year-old male child. The child presented with severe headache after which MRI was done. It was suggestive of pineal region low-grade tumor. The patient was operated in Parkbench position with SCIT (supracerebellar approach) in a retractor-free manner. Gross total resection was done. However, the patient developed postoperative left-sided hemiparesis. It got improved in 1 month, and the patient became ambulatory. Histopathology came out as pleomorphic xanthoastrocytoma.

Conclusion: Surgical management should include careful resection near the internal capsule to avoid postoperative hemiparesis. Also, shunt should be delayed in the cystic cavity created by resection of tumor.
\end{abstract}

Keywords: Pleomorphic xanthoastrocytoma, Pineal region, Thalamus, Supracerebellar infratentorial

\section{Background}

Pineal region tumors are very rare. It consists of 0.4 to $1.0 \%$ of all intracranial tumors in adults and 3.0 to $8.0 \%$ of brain tumors in children. It has multiple variations in histology from a benign one to malignant type. They are divided into germ cell and non-germ cell derivatives [1]. Majority of them occurs either due to displaced embryonic tissue or due to malignant transformation of the pineal parenchymal cells. Some have suggested its presence because of transformation of the surrounding astroglia [2]. The occasional gliomas seen in the pineal region are usually pilocytic astrocytomas (PCA), oligodendroglioma, and ganglioglioma, which are thought to arise from resident pineal astroglial cells $[3,4]$.Throughout the search of different literatures, very few cases of

\footnotetext{
* Correspondence: dr.sarajkumarsingh@gmail.com

${ }^{1}$ Department of Neurosurgery, AllMS Patna, Bihar, India

Full list of author information is available at the end of the article
}

pleomorphic xanthoastrocytoma (PXA) of the pineal region have been reported so far $[5,6]$. The author is reporting a rare case of such tumor at the pineal region. Its pleomorphic histology along with diagnostic features and surgical management are being discussed in details.

\section{Case presentation}

An 11-year-old boy reported to the outpatient department with a history of gradual onset of severe headache for 2 months. There was no history of vomiting, seizure, and focal deficits. On examination, the patient was E4 M6 V5. Vitals are stable; pupil is in normal size reacting to light. Ocular movements were within normal limits. Motor and sensory examination was normal. Past history and family history were insignificant. The patient came with non-contrast computerized tomography (NCCT) head (Fig. 1a). It was showing cystic mass in the lateral ventricle measuring $2.5 \times 2.3 \times 2 \mathrm{~cm}$ with enhancing 


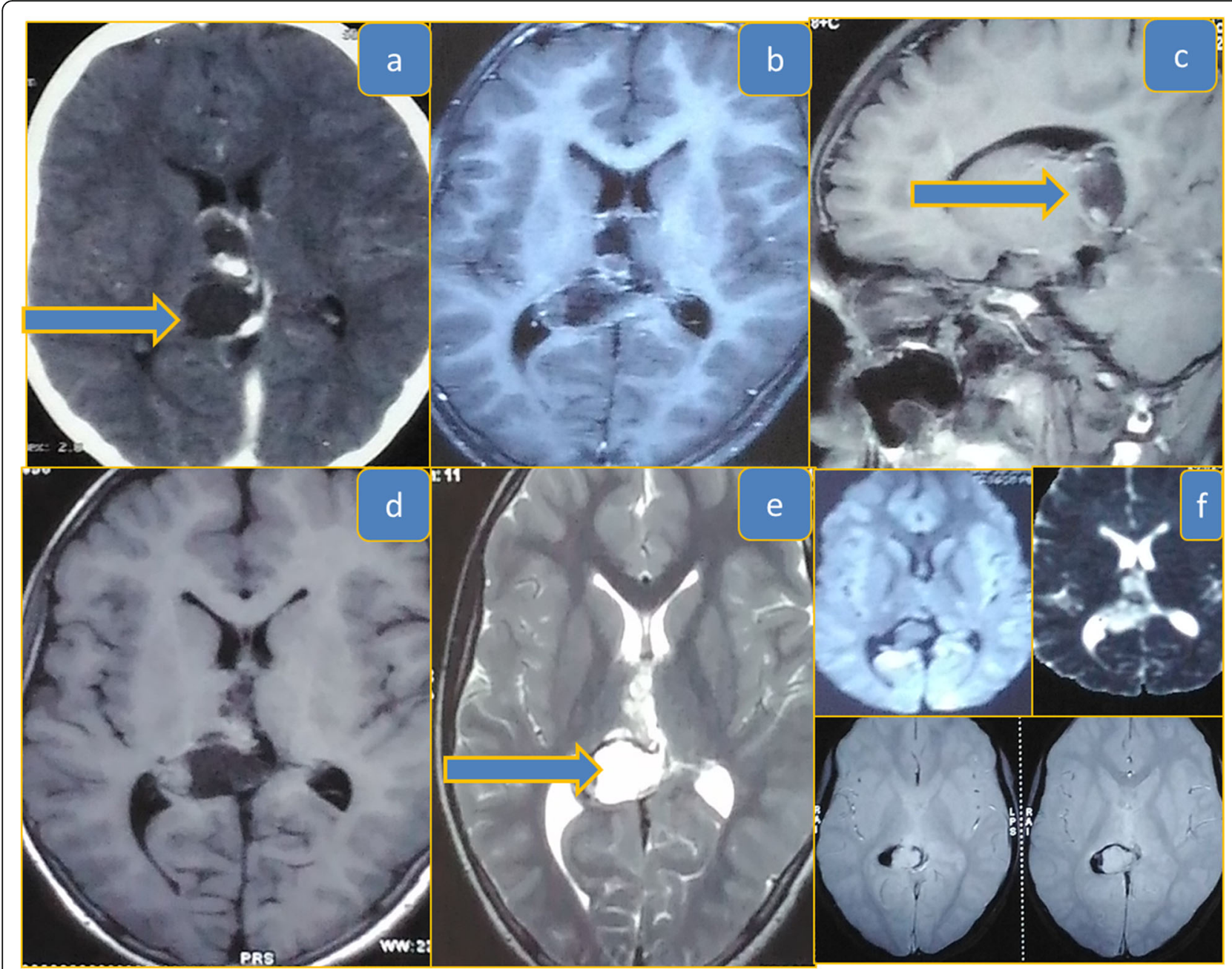

Fig. 1 a CECT head (axial) showing enhancing cystic mass at the posterior 3rd ventricle (arrow mark). b, c Contrast T1 (axial) and contrast T1 (sagittal) showing minimally enhancing cystic mass at the posterior 3rd ventricle. $\mathbf{d}, \mathbf{e} \mathrm{T} 1$ axial sequence showing hypointense and T2 axial showing hyperintense. Mass (arrow mark) at the posterior 3rd ventricle. f Axial sections of diffusion-weighted (DWI) and ADC showing no restriction and gradient sequence MRI showing blooming at periphery of the lesion (arrow mark)

capsule. Contrast-enhanced magnetic resonance imaging (CEMRI) of the brain was suggestive of cystic mass at the posterior part of the 3rd ventricle measuring $3 \times 2.5$ $\times 2.5 \mathrm{~cm}$ in mass. It was hypointense on $\mathrm{T} 1$ and hyperintense on T2, with patchy enhancement of the wall on contrast without any diffusion restriction without any hydrocephalus (Fig. 1b-f).

The patient was operated in Parkbench position with SCIT approach (supracerebellar infratentorial). Suboccipital craniotomy was done after linear midline incision. The superior aspect of the cerebellum was detethered from the tentorium. Precentral cerebellar vein was identified and preserved. The tumor was approached with oblique trajectory. The tumor was grayish to yellow, soft, suckable, completely filling the third ventricle, and non-vascular with well-defined plane. Gross total resection was done. Intraoperatively, the procedure was uneventful.

The patient was extubated on the same day. However, the patient developed postoperative left-sided hemiparesis. It got improved in 1 month, and the patient became ambulatory. Postoperative NCCT head on day 1 was showing clear but dilated operative cavity, without any residual or operative cavity hematoma with mild pneumocephalus (Fig. 2a). There was mild ventriculomegaly, but periventricular ooze was absent. Serial NCCT head was done on postoperative days 3 and 4. There was disappearance of pneumocephalus. The operative cavity was gradually shrinking. Ventriculomegaly and periventricular ooze was absent (Fig. 2b, c). The patient was hemodynamically stable throughout the stay. On follow-up, the patient has shown 


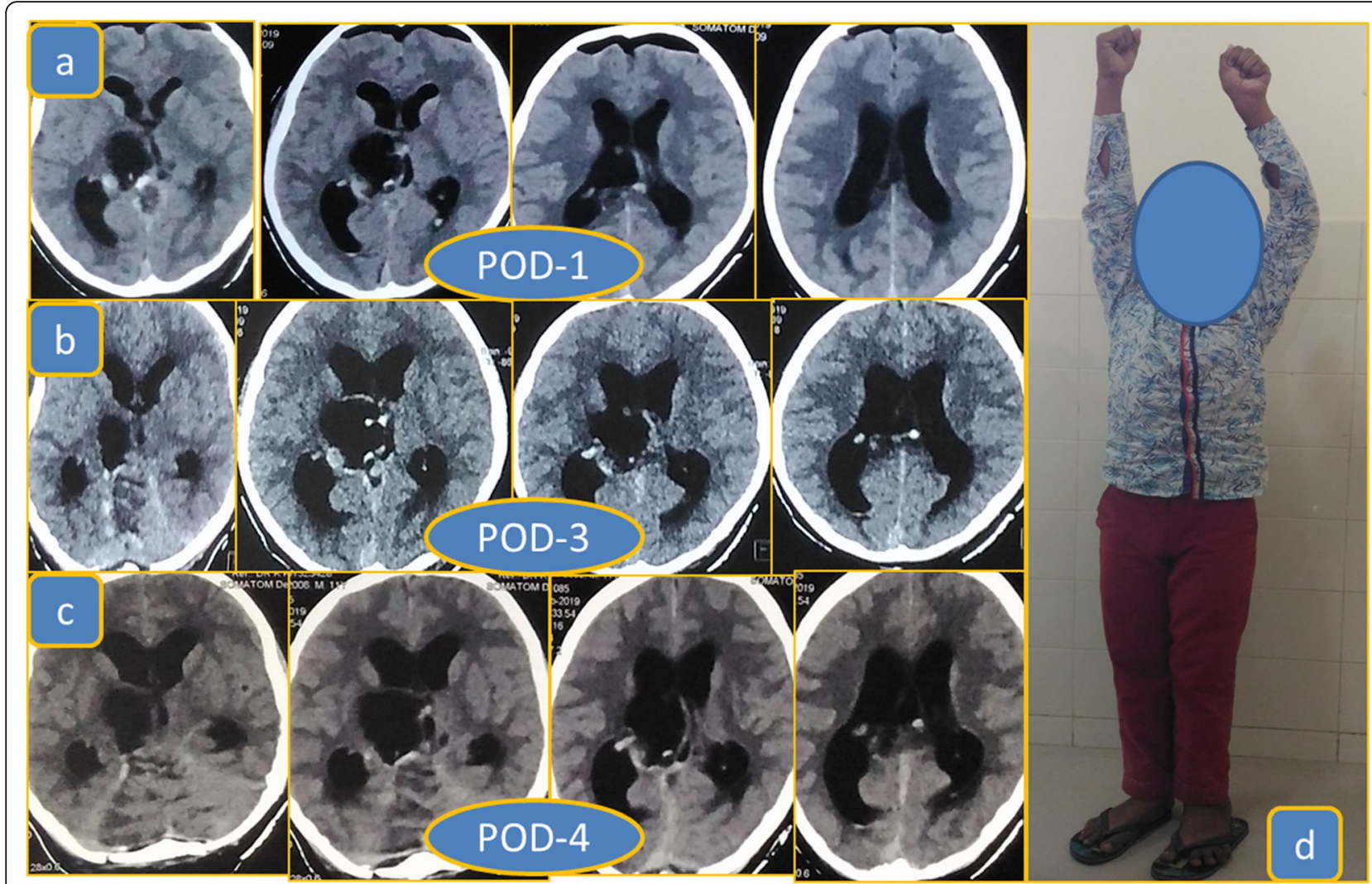

Fig. 2 a Postoperative NCCT head on postoperative (POD) 1 showing minimal pneumocephalus, clear operative cavity, mild ventriculomegaly, and no periventricular ooze. b, c Post-operative NCCT head on POD days 3 and 4 showing good and communicating operative cavity without any hematoma, with mild ventricle dilatation, without any periventricular ooze. $\mathbf{d}$ Showing postoperative image of the patients in standing position with improved power in the left upper limb

improvement in hemiparesis and he became ambulatory (Fig. 2d). The left upper limb power regained $80 \%$ at 6 months follow-up.

The tumor sections show a glial tumor arranged in fascicles and diffuse sheet $(H \& E \times 20, \times 100)$. Tumor cells are round to oval, showing moderate nuclear pleomorphism, hyperchromatic nuclei, and vacuolated to eosinophilic cytoplasm in few of them; few bizarre cells and giant cells are also seen $(H \& E \times 400)($ Fig. $3 a-d)$.

\section{Discussion}

Majority of the tumors at the pineal region are extensions from the adjacent structures and ventricles rather than arising from the core pineal parenchyma. The tumor in our patient was arising from the adjacent thalamus and extending into the ventricles. It has been highlighted that along with astrocytes and interstitial cells of the pineal gland, ependymal cells of ventricles also contribute to tumor mass [7]. It is possible that the range of tumor histology encountered among these pleomorphic neoplasms is a result of varying degrees of contribution from local cell populations. The pineal region tumors encompass a wide spectrum of histology ranging from benign to malignant. Pineal region glioblastoma multiforme is a major differential diagnosis at this region for PXA. However, absence of atypical mitosis and necrosis was suggestive of low-grade tumor [8]. And the presence of nuclear pleomorphism along with giant cells and vacuolated eosinophilic cytoplasm was more in favor of PXA.

PXA is a rare intra-axial tumor of young adults. It is having two varieties, distinguishable by the presence or absence of a cyst. The cystic variant is reported to have a more benign clinical course and tends to be restricted in the pineal gland. In our case, tumor was largely cystic with widespread extension into the adjacent structures [9].

Pineal parenchymal tumor with astrocytic differentiation is also one of the differential diagnoses for PXA. However, it occurs mostly in old age. Also, pineal parenchymal tumors are positive for synaptophysin. In our case, it was negative [10]. Most of these patients present with symptoms of increased intracranial pressure. Patients may also present with Parinaud's syndrome, gait disturbances, seizures, and 


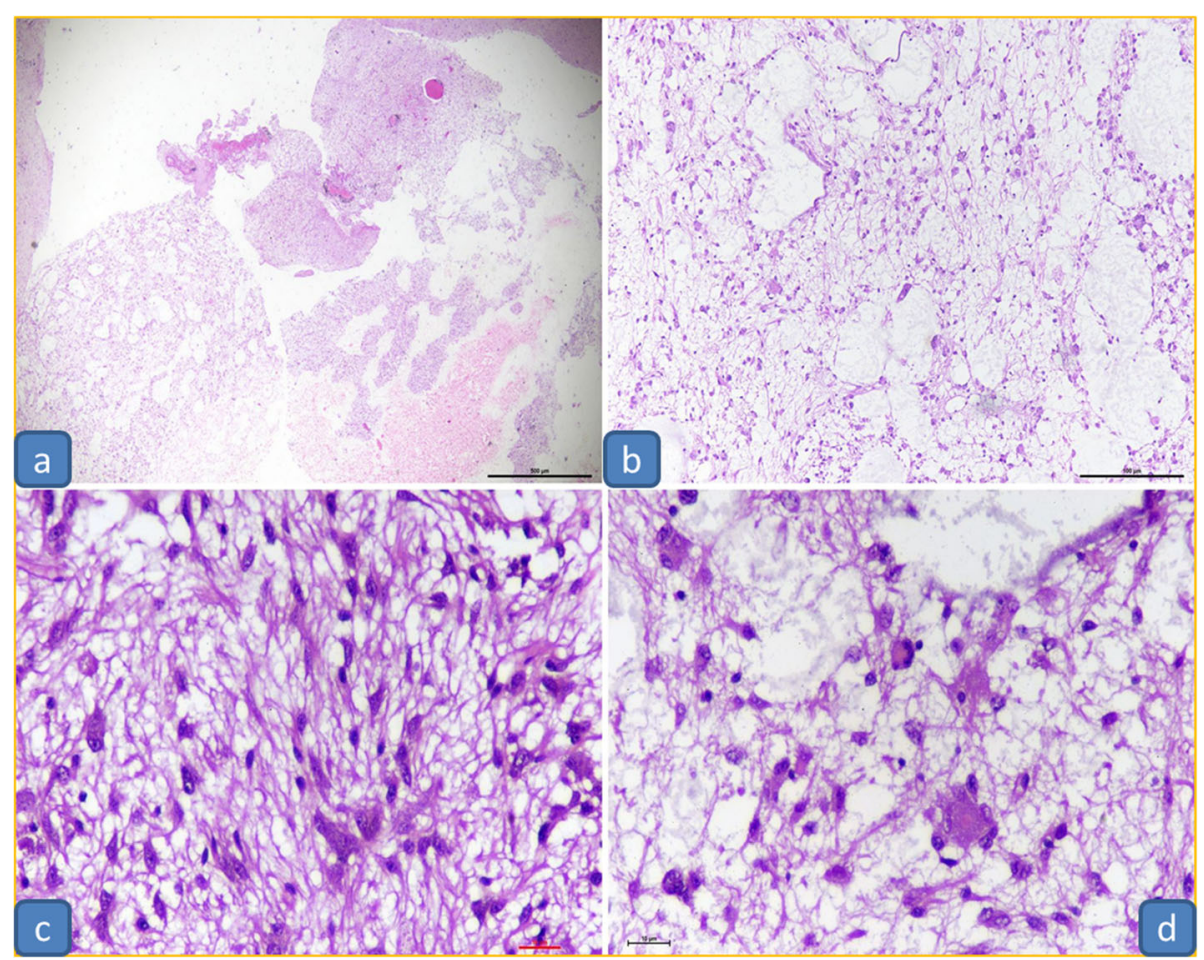

Fig. 3 a A glial tumor arranged in fascicles and diffuse sheet $(H \& E \times 20, \times 100)$. b, c The tumor cells are round to oval, which show moderate nuclear pleomorphism, hyperchromatic nuclei, and vacuolated to eosinophilic cytoplasm in few of them (arrow) (H\&E; X400). d Few bizarre cells and giant cells are also seen $(H \& E \times 400)$

cranial nerve palsies. The favorable prognosis of these tumors in the absence of characteristic radiological appearance emphasizes the role for histological confirmation of all pineal region tumors. Pineal cysts are a common imaging finding with a reported frequency of $25-40 \%$ in autopsy series. It is difficult to distinguish low-grade cystic gliomas versus pleomorphic xanthoastrocytomas versus more common pineal cyst in the pineal region. However, due to overlapping radiological and clinical presentations, histological examination is important to differentiate between these three $[7,11]$.

Open surgery is still considered the treatment of choice for pineal region tumors and pineal parenchymal tumors, for adequate tissue acquisition and better progression-free survival. Surgical approach should be well balanced to provide maximum resection with minimal postoperative deficits. The anatomical location of the tumor, the neurosurgeon's familiarity towards certain approach, and the patient's anatomical variation all aid in the choice of the best approach. In general, the three adopted approaches to the pineal region include the following: the supracerebellar infratentorial (SCIT), the occipital transtentorial, the transcallosal interhemispheric approaches, and less commonly the transcortical transventricular approach [12, 13]. Thakkar et al. had utilized modified Poppen's approach for dealing pineal region PXA in their case [14]. The location of the vein of Galen and internal cerebral vein should be identified in relation to the pineal region tumor before opting for suitable approach. Supracerebellar infratentorial is an ideal approach for tumors having minimal supratentorial extension with postero-superiorly displaced great vessels.

For pineal region PXA, there is not much literature regarding follow-up and identification of recurrence. However, as it is a benign tumor, behavior should be more like other benign pineal parenchymal tumors like pineocytoma. In pineocytomas, the recurrence rate is negligible after complete resection of the tumor. But there is a 9.5\% rate of recurrence after subtotal resection [13].

The pineal region is the area where risk versus benefit ratio should be balanced as any type of injury to vessel is difficult to control due to long distance from the surface, big open cavity, and multiple communicating channels to ventricles which can easily nullify the tamponade effect of cottons balls used for hemostasis.

It has been reported that bridging veins between the tentorium and the cerebellum can be safely sacrificed [15]. But few authors have focused on preserving these veins due to danger of edema and venous infarction of the cerebellum that they have encountered in their patients [16]. Jakola et al. has reported cerebellar venous infarction after the scarification of a single bridging vein 
through a paramedian approach [17]. Therefore, our operative target is to always preserve large veins even if it looks non-eloquent. And smaller thin-walled veins can be sacrifices. Intraoperatively, only dynamic retraction should be done and any type of static retraction should be avoided as continuous stretching of the bridging veins can result in injury and thrombosis along with cerebellar edema [18]. For dynamic retraction, the shaft and or tip of the suction cannula and brain spatula (intermittent application by assistant) can be utilized [18].

According to our experience, nature and consistency of the tumor is one of the major factors for deciding whether to sacrifice the precentral vein or not. Patients with soft and cystic low-grade tumor which is easily suckable (as in our patient) can go tumor decompression and excision from the corridors lateral to the precentral vein (corridor between precentral vein and basal vein). In low-grade gliomas like PCA or PXA, tumors are loosely attached to the precentral vein or other vessels which can be slowly peeled off or may be left behind if needed. If the tumor is firm and densely attached, handling from the corridors become more difficult, making the vessel more prone to injury. Intraoperative inadvertent injury can contaminate the operative field which can be energy sapping for neurosurgeons. Therefore precentral vein can be tried to preserve if the tumor is soft and cystic, with well-defined plane from the vessel or loosely attached to vessels $[13,18]$.

\section{Conclusions}

To conclude, clinical and radiological features of the pineal region tumors may differ, but accurate histopathology confirms the site of origin. However, the approach to the pineal region should be utilized in judicious manner to provide a disease-free and disability-free life to the patient.

\section{Abbreviations}

PXA: Pleomorphic xanthoastrocytoma; SCIT: Supracerebellar infratentorial; NCCT: Non-contrast computed tomography

\section{Acknowledgements}

Dr. Yashmin, Junior Resident, Neurosurgery

\section{Authors' contributions}

All authors have read and approved the manuscript. SKS - acquisition and analysis of data, study design, and drafting and editing of manuscript. KKS-proofreading. TK-histopathology report and photomicrographs.

\section{Funding}

None.

\section{Availability of data and materials}

Written consent to publish this information was obtained from the patient and his mother.

\section{Declarations}

Ethics approval and consent to participate Not applicable.

\section{Consent for publication}

The patient and his mother have given their written informed consent to publish their case (including publication of images).

\section{Competing interests}

The authors declare that they have no competing interests.

\section{Author details}

${ }^{1}$ Department of Neurosurgery, AllMS Patna, Bihar, India. ${ }^{2}$ Department of Pathology, AllMS Patna, Bihar, India.

Received: 4 November 2020 Accepted: 15 April 2021

Published online: 12 July 2021

\section{References}

1. Giannini C, Paulus W, Louis DN, et al. Pleomorphic xanthoastroma. In: Louis DN, Ohgaki H, Wiestler OD, Cavenee WK, editors. World Health Organization classification of tumors. WHO classification of tumours of the central nervous system. 4th ed. Lyon: IARC Press. p. 22-4.

2. Regis J, Bouillot P, Rouby-Volot F, et al. Pineal region tumors and the role of stereotactic biopsy: review of the mortality, morbidity, and diagnostic rates in 370 cases. Neurosurgery. 1996;39:907-14.

3. De Girolami U, Ambrustmache WW. Juvenile pilocytic astrocytoma of the pineal region: report of a case. Cancer. 1982;50(6):1185-8. https://doi.org/1 0.1002/1097-0142(19820915)50:6<1185::AID-CNCR2820500626>3.0.CO;2-A.

4. Vaquero J, Ramiro J, Martinez R. Glioblastoma multiforme of the pineal region. J Neurosurg Sci. 1990;34(2):149-50.

5. Srinivas BH, Uppin MS, Panigrahi MK, Saradhi MV, et al. Pleomorphic xanthoastrocytoma of the pineal region. J Clin Neurosci. 2010;17(11):1439-41. https://doi.org/10.1016/j.jocn.2010.02.022.

6. Hanna JA, Mathkour M, Gouveia EE, et al. Pleomorphic xanthoastrocytoma of the pineal region in a pediatric patient with neurofibromatosis type 1. Ochsner J. 2020;20(2):226-31. https://doi.org/10.31486/toj.18.0156.

7. Praver M, D'Amico R, Arraez C, Zacharia BE, Varma H, Goldman JE, et al. Atypical pleomorphic neoplasms of the pineal gland: case report and review of the literature. Surg Neurol Int. 2015;6(1):129. https://doi.org/10.41 03/2152-7806.161790.

8. Kepes JJ, Rubinstein LJ, Ansbacher L, Schreiber DJ. Histopathological features of recurrent pleomorphic xanthoastrocytoma: further corroboration of the glial nature of this neoplasm. Acta Neuropathol. 1989;78(6):585-93. https://doi.org/10.1007/BF00691285.

9. Kepes JJ, Rubinstein LJ, Eng LF. Meningocerebral xanthoastrocytoma. A distinctive glioma in young subjects, presumably originating from subpial astrocytes, with relatively favorable prognosisAbstracts of the 8th International Congress of Neuropathology, Washington, DC. Am Assoc Neuropathol. 1978;37(5):641. https://doi.org/10.1097/00005072-19780900000221.

10. Borit A, Blackwood W. Pineocytoma with astrocytomatous differentiation. J Neuropathol Exp Neurol. 1979;38(3):253-8. https://doi.org/10.1097/ 00005072-197905000-00006.

11. Pu Y, Mahankali S, Hou J, Li J, Lancaster JL, Gao JH, et al. High prevalence of pineal cysts in healthy adults demonstrated by high-resolution, noncontrast brain MR imaging. AJNR Am J Neuroradiol. 2007;28(9):1706-9. https://doi. org/10.3174/ajnr.A0656.

12. Bruce JN, Ogden AT. Surgical strategies for treating patients with pineal region tumors. J Neuro-Oncol. 2004;69(1-3):221-36. https://doi.org/10.1023/ B:NEON.0000041885.09226.2d.

13. Abbassy M, Aref K, Farhoud A, Hekal A. The supracerebellar infratentorial approach in pineal region tumors: technique and outcome in an underprivileged setting. Alexandria J Med. 2018;54(4):725-9. https://doi. org/10.1016/j.ajme.2018.02.003.

14. Thakar S, Sai Kiran NA, Ghosal N, Hegde AS. Pleomorphic xanthoastrocytoma: a new differential diagnosis for a pediatric pineal neoplasm. Brain Tumor Pathol. 2012;29(3):168-71. https://doi.org/10.1007/s1 0014-011-0076-7.

15. Hernesniemi J, Romani R, Albayrak BS, Lehto H, Dashti R, Ramsey C III, et al. Microsurgical management of pineal region lesions: personal experience with 119 patients. Surg Neurol. 2008;70(6):576-83. https://doi.org/10.1016/j. surneu.2008.07.019.

16. Bruce JN, Stein BM. Surgical management of pineal region tumors. Acta Neurochir. 1995;134(3-4):130-5. https://doi.org/10.1007/BF01417679. 
17. Jakola AS, Bartek J Jr, Mathiesen T. Venous complications in supracerebellar infratentorial approach. Acta Neurochir. 2013;155(3):477-8. https://doi.org/1 0.1007/s00701-012-1614-8.

18. Matsuo S, Baydin S, Gungor A, et al. Midline and off-midline infratentorial supracerebellar approaches to the pineal gland. J Neurosurg. 2017;126(6): 1984-94. https://doi.org/10.3171/2016.7.JNS16277.

\section{Publisher's Note}

Springer Nature remains neutral with regard to jurisdictional claims in published maps and institutional affiliations.

Submit your manuscript to a SpringerOpen ${ }^{\circ}$ journal and benefit from:

- Convenient online submission

- Rigorous peer review

- Open access: articles freely available online

- High visibility within the field

- Retaining the copyright to your article

Submit your next manuscript at $\boldsymbol{\sim}$ springeropen.com 